\title{
Effects of feeding commercial diets on the development of juvenile crucian carp Carassius carassius: digestive tract abnormalities
}

\author{
Robert Kasprzak*, Teresa Ostaszewska, Maciej Kamaszewski \\ Department of Ichthyology and Biotechnology, in Aquaculture, Institute of Animal Science, \\ Warsaw University of Life Sciences SGGW, 02-787 Warsaw, Poland
}

\begin{abstract}
Wild-living populations of the crucian carp Carassius carassius, a cyprinid fish of European freshwaters, have decreased in recent years, likely due to increasing competition presented by invasive species. Several initiatives have been launched in an attempt to reintroduce this fish back into its natural habitat, but these approaches require the use of crucian carp fry reared under controlled conditions, and the use of popular and inexpensive commercial diets has been found to result in developmental abnormalities. The aim of the current study was to analyse the impact of feeding juvenile crucian carp either natural food (Chironomidae sp. larvae) or 2 commercial diets, with a focus on the intestinal development of these fish. Histological analysis revealed significant pathologies in the alimentary tracts of fish fed both commercial diets; these included lowered hepatocyte and enterocyte proliferation, as well as shortened intestinal folds. Furthermore, the digestive enzyme activity patterns suggested a physiological state close to malnutrition. This study confirmed that basic commercial diets (at least the 2 applied) are not recommended for the rearing of crucian carp juveniles, even though initial growth rates of the fish might suggest otherwise.
\end{abstract}

KEY WORDS: Commercial diets · Crucian carp $\cdot$ Intestinal abnormalities $\cdot$ Histology $\cdot$ Digestive enzymes

\section{INTRODUCTION}

The crucian carp Carassius carassius is a cyprinid species which was originally autochthonic to the freshwaters of central and northern parts of Europe and Asia (Sayer et al. 2011). In recent years, a sudden decline of natural $C$. carassius populations throughout Europe has been reported (Tarkan et al. 2009, Sayer et al. 2011). The main cause of this phenomenon appeared to be the coinciding growth of wild populations of the Prussian carp Carassius gibelio and the common goldfish Carassius auratus, both of which are considered invasive in this part of the world (De Giosa et al. 2014, Ribeiro et al. 2015). They occupy the same ecological niche as the crucian carp and thus constitute competition that this species has never faced before (Sayer et al. 2011). Additionally,

${ }^{*}$ Corresponding author: robert_kasprzak@sggw.pl they disrupt the genetic pool of C. carassius due to crossbreeding and are also able to reproduce via gynogenesis (Tarkan et al. 2012, Wouters et al. 2012). In aquaculture, hybrids of the crucian carp with the common carp Cyprinus carpio are valued, but they also are a threat to wild-living populations (Hänfling et al. 2005).

Ever since the total extinction of the crucian carp in European waters became a real threat, the demand for these fish reared in aquaculture has grown, and several reintroduction projects have been launched aiming to restore wild populations (Tarkan et al. 2009, 2016, Sayer et al. 2011). However, because of the expansion of invasive species, the aquaculturereared crucian carps need to be in the best physical condition possible upon release, in order to have higher odds of survival and propagation and to with-

() The authors 2019. Open Access under Creative Commons by Attribution Licence. Use, distribution and reproduction are unrestricted. Authors and original publication must be credited. 
stand the awaiting environmental challenges. Recently, angling organizations also revealed an increasing interest in the crucian carp, which has only added to the growing demand for cultivated C. carassius fry (Żarski et al. 2011, Demény et al. 2012). These 2 different demands (ecological and commercial) are the main reasons that an adequate breeding program should be developed for this species.

Rearing protocols for the crucian carp are yet to be refined, and the selection of a proper starting diet appears to be the most troublesome aspect. Although C. carassius larvae and juveniles fed natural food grow quickly and appear to be in a good physical condition (Żarski et al. 2011, Demény et al. 2012), such feeds always generate enormous costs for the producers when used on a large scale. The application of commercial diets would allow producers to overcome this issue, but crucian carp need to be fed natural food (Artemia nauplii) for at least 1 mo posthatching before any dry diets may be introduced (Łączyńska et al. 2016), and feeding some of the popular commercial diets to $C$. carassius juveniles has been found to result in skeletal deformities (Myszkowski et al. 2002, Kasprzak et al. 2019). Other physiological and morphological aspects of juvenile development of this species, however, have not been studied or described.

The overall performance of fish passing early stages of ontogenesis can be assessed by studying both the physiology and morphology of the developing alimentary tract, as these are important indicators of the processes of digestion and absorption of nutrients (Izquierdo et al. 2000, Kamaszewski et al. 2010). One of the most effective and commonly acknowledged methods applied in studies on intestinal physiology of fish larvae or juveniles is the activity analysis of digestive and brush border enzymes (BBEs) (Zambonino-Infante \& Cahu 2007), while histomorphometric measurements of enterocytes are helpful in the examination of intestinal morphology (Ostaszewska et al. 2005).

In this study, the development of 1 mo old crucian carp juveniles was examined after feeding them with popular, commercial dry feeds. Feeding experiments usually give precise information about the effects of the nutritional deficiency or overdose of a specific dietary ingredient because they involve the use of formulated diets. To date, however, only a handful of studies have more thoroughly described any of the developmental processes occurring during the early ontogenesis of crucian carp fed dry diets (Eaczyyńska et al. 2016), which is why 2 commercial feeds, both common in Polish aquaculture, were used in this study as a representation of rearing practices carried out by fish producers. Chironomidae larvae were chosen for the control feeding group to act as a representation of natural food, presumably obtained by these fish in the wild.

Activity analysis of digestive enzymes and BBEs was used for the comparison of intestinal development along with histomorphometric measurements of several parameters of the alimentary tract. This paper is a continuation of a previously published article (Kasprzak et al. 2019), which described skeletal deformations in these studied fish.

\section{MATERIALS AND METHODS}

\subsection{Experimental set-up}

Crucian carp larvae ( $3 \mathrm{~d}$ post hatching, dph) were stocked in nine 201 tanks at an initial density of 20 larvae $\mathrm{l}^{-1}$. The tanks were placed in a water recirculation system (water flow through the tanks was constant at $0.41 \mathrm{~min}^{-1}$ ) equipped with mechanical and biological filtration and UV irradiation. Water temperature $\left(25 \pm 0.5^{\circ} \mathrm{C}\right)$ and dissolved oxygen levels $\left(8.3 \pm 0.8 \mathrm{mg} \mathrm{l}^{-1}\right)$ were controlled at each feeding. The $\mathrm{pH}(8.0 \pm 0.1$; pH-meter: 3110 SET 2; WTW) and concentration of basic organic ions was measured once $\mathrm{d}^{-1}$. Ion concentrations did not exceed the following values (ppm): $0.1\left(\mathrm{NH}_{4}{ }^{+}\right), 10\left(\mathrm{NO}_{3}{ }^{-}\right), 0.1\left(\mathrm{NO}_{2}{ }^{-}\right)$and $0.05\left(\mathrm{PO}_{4}^{-} ;\right.$colorimetric tests: JBL Testlab). Stocking density and water parameters were chosen appropriately for the species (Żarski et al. 2011, Sikorska et al. 2018). Fish were exposed to light for $13 \mathrm{~h} \mathrm{~d}^{-1}$. Tanks were cleaned twice $\mathrm{d}^{-1}$; dead fish were removed during the maintenance of the tanks, and mortality values were calculated.

All larvae were fed Artemia sp. nauplii, ad libitum, 5 times $\mathrm{d}^{-1}$ (every $3 \mathrm{~h}$ ) over the first 4 wk of rearing. After that, 30 sampled fish were weighed (mean body mass $=54.03 \pm 13.63[\mathrm{SD}] \mathrm{mg} ;$ scale: WPS $60 / \mathrm{C} / 10$; Radwag) and measured (mean standard length = $13.31 \pm 0.8$ mm; caliper: Z22855; Milomex), and classified as the starting-point 'zero' group. The number of remaining fish was unified in each aquarium to account for minor early larval mortality, and the fish were divided into 3 experimental groups; each group was replicated in triplicate (stocking density $=18$ larvae $1^{-1}$ ). Water parameters remained unchanged and were measured in the same way as before.

Fish in group $N$ (natural food treatment) were fed frozen Chironomidae sp. larvae, representing a natural diet. Meanwhile, starter diets $X$ or $Y$ were applied 
to experimental food treatment groups $X$ or $Y$, respectively. According to their manufacturers, both commercial diets are suitable for many different fish groups, but only diet $X$ was recommended for cyprinids (specifically, the common carp).

Feeding frequency remained as it was previously (every $3 \mathrm{~h}, 5$ times $\mathrm{d}^{-1}$ ). Feeding rations on Day 1 were $25 \%$ (group $N$ ) and $4 \%$ (groups $X$ and $Y$ ) of the biomass. The portions were raised slightly each day to account for the nutritional demands of the growing fish. Fish samples were obtained after 2, 4 and $6 \mathrm{wk}$ of the experiment. Body mass measurements after Weeks 2 and 4 were used for recalculating biomass to determine new feeding rations, following the pattern mentioned above and keeping the biomass percentage values unchanged. Intermediate body mass measurements also allowed for calculation of the specific growth rate (SGR, \% d ${ }^{-1}$; Ricker 1979), which was recorded separately for each of the three $2 \mathrm{wk}$ long periods $(0-2,2-4$ and $4-6 \mathrm{wk})$. Basic food composition was analysed according to AOAC methods, while the $\mathrm{Ca}, \mathrm{P}$ and $\mathrm{Mg}$ content was measured with inductively coupled plasma-mass spectrometry (ICPMS). Carbohydrates were calculated by subtracting the other 4 basic parameters from the dry matter (DM). All parameters are presented in Table 1.

\subsection{Sample fixation and body content analysis}

Sampled fish were anaesthetized with MS-222 at $4^{\circ} \mathrm{C}$ and then weighed and measured (mean of 30 fish group ${ }^{-1}$ ). For whole-body content analysis, fish were frozen and stored at $-80^{\circ} \mathrm{C}$. For histology, fish were fixed in $4 \%$ paraformaldehyde in phosphatebuffered saline (PBS) $\left(24 \mathrm{~h}, 4^{\circ} \mathrm{C}\right)$, flushed with dis-

Table 1. Nutritional content of the experimental diets ( $N$ : natural food [Chironomidae sp. larvae]; $X$ and $Y$ : commercial starter diets) provided to juvenile crucian carp $\left(\mathrm{g} \mathrm{kg}^{-1}\right.$ dry matter [DM]). Diet DM: N: 163.3; X: 925.2; Y: $911.4\left(\mathrm{~g} \mathrm{~kg}^{-1}\right.$ of wet weight)

\begin{tabular}{|lrrr|}
\hline & Natural diet & \multicolumn{2}{c|}{ Commercial diets } \\
& $N$ & \multicolumn{1}{c}{$X$} & $Y$ \\
\hline Total protein & 520.3 & 643.3 & 664.1 \\
Total fat & 18.0 & 119.7 & 101.9 \\
Crude fiber & 74.4 & 11.5 & 2.5 \\
Carbohydrates & 73.3 & 126.7 & 112.7 \\
Ash & 314.0 & 98.8 & 118.8 \\
Ca & 32.4 & 14.7 & 23.8 \\
P & 7.1 & 15.5 & 19.7 \\
$\mathrm{Mg}$ & 6.0 & 2.2 & 2.1 \\
\hline
\end{tabular}

tilled water and stored in $70 \%$ ethanol at $4^{\circ} \mathrm{C}$. For enzymatic analyses, fish were frozen in liquid nitrogen and preserved at $-80^{\circ} \mathrm{C}$.

For the total body content analysis, the DM, ash, total protein and crude fat were analysed according to AOAC methods. All measurements were conducted in triplicate, in pooled samples (60 fish group $^{-1}$ ) taken after $6 \mathrm{wk}$ of the trial.

\subsection{Digestive tract analyses}

Histological analysis of the digestive tract was conducted in non-decalcified fish taken after 6 wk (12 fish group $^{-1}$ ). They were dehydrated in ethanol, processed through xylene and finally embedded in paraffin, then cut longitudinally ( $6 \mu \mathrm{m})$ on a RM 2265 microtome (Leica Microsystems). General observations and histomorphometric measurements of the digestive tract were made on slides stained with either AB-PAS $(\mathrm{AB} \mathrm{pH}=2.5)$, hematoxylin \& eosin or immunohistochemically with either a monoclonal mouse antibody directed against the proliferating cell nuclear antigen (PCNA) or a polyclonal rabbit anti-caspase-3 antibody (Bakke-McKellep et al. 2007; adapted to paraffin-embedded slides by Ostaszewska et al. 2008). Incubation with the primary antibody lasted either $1 \mathrm{~h}$ (antiPCNA: dilution 1:300, Clone PC10; Dako) or overnight (anti-caspase-3: dilution 1:200, G7481; Promega), then for $30 \mathrm{~min}$ with the secondary polymer (EnVision+ System-HRP; Dako). Visualization with the use of DAB chromogen (peroxidase substrate) lasted $40 \mathrm{~s}$. Slides incubated without the primary antibody were used as a negative control. Harris' hematoxylin was used as a counter-stain.

All histomorphometric measurements were done using the NIS-Elements AR Image Analysis System, with an ECLIPSE 90i microscope and DS5-UI camera (all elements: Nikon Corporation). A single field of view (FOV) area at $400 \times$ magnification was $35000 \mathrm{\mu m}^{2}$. The following digestive tract parameters were measured: hepatocyte proliferation and apoptosis (in 60 FOVs group $^{-1}$; Ostaszewska et al. 2016; an example of hepatocyte apoptosis is shown in Fig. 1), nuclear, cellular and lipid area of hepatocytes, as well as nuclear, cellular and zymogenic area of exocrine pancreatic cells (each in 600 cells group $^{-1}$; Ostaszewska et al. 2005, Napora-Rutkowski et al. 2009, Kamaszewski et al. 2010), enterocyte proliferation (in 60 crypts group $^{-1}$; Bakke-McKellep et al. 2007), intestinal fold height (in 180 folds group ${ }^{-1}$; Baeverfjord \& Krogdahl 1996) and proportion of acidic, neutral and mixed mucous cells in the intes- 


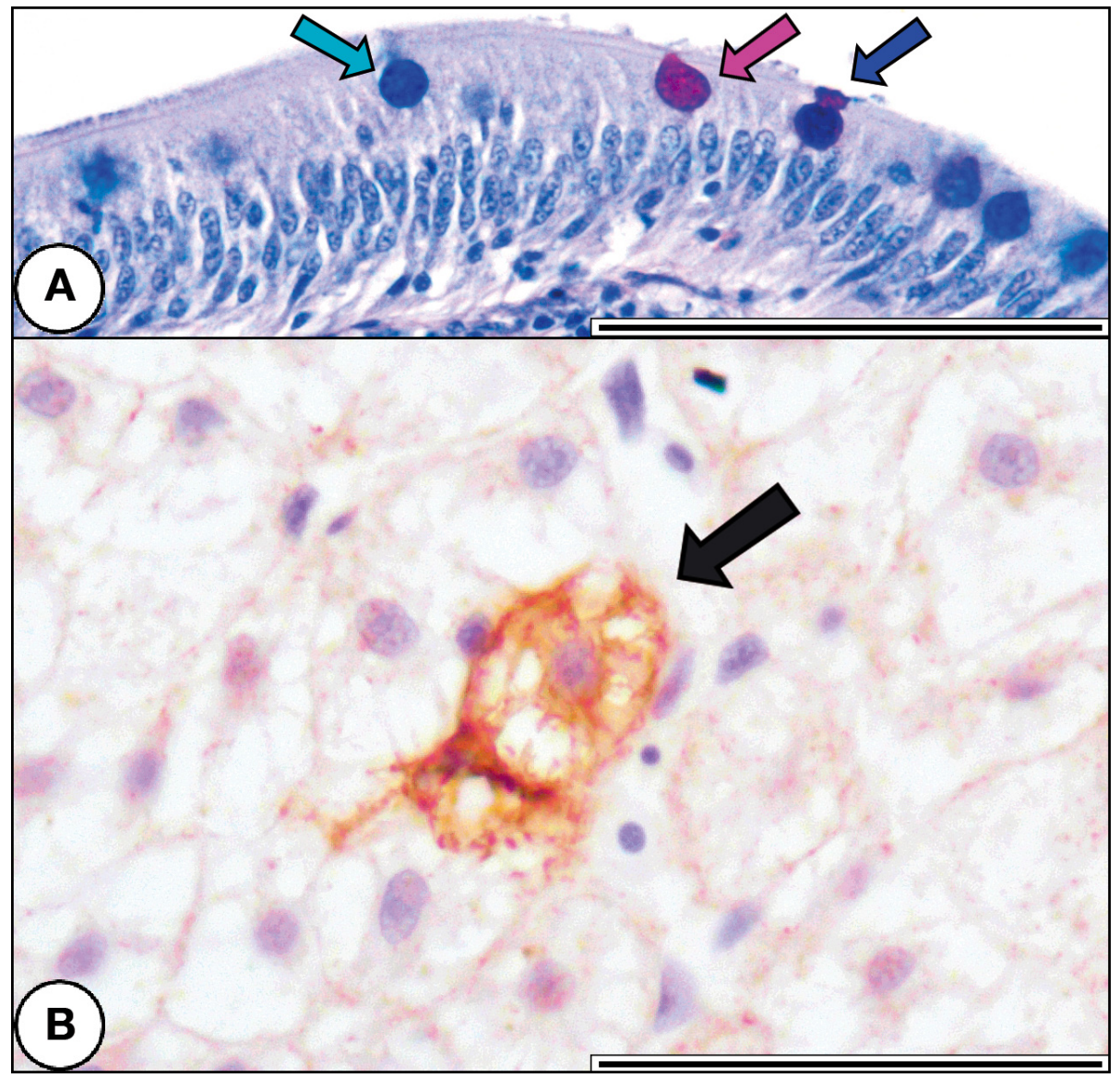

Fig. 1. Exemplary sections of (A) intestinal mucosa and (B) liver of a juvenile crucian carp from group $N$ (fed a natural diet), after $6 \mathrm{wk}$ of the feeding experiment. In (A), arrows indicate 3 different recognized and quantified types of mucous cells: acidic (light-blue), neutral (pink) and mixed (dark-blue); in (B), arrow indicates an apoptotic hepatocyte. AB-PAS stain (A) and immunohistochemical stain with anti-caspase-3 polyclonal antibody, counterstained with hematoxylin (B); scale $=100 \mu \mathrm{m}$

tinal epithelium (in 60 FOVs group ${ }^{-1}$, calculated as the percentages of these 3 types of mucous cells separately for each specimen; cells were recognized as in Fig. 1).

For the enzymatic activity analysis, digestive tracts were obtained from rapid frozen fish (12 fish group ${ }^{-1}$ at every sampling point; total $\mathrm{n}=120$ ), then homogenised and subjected to spectrophotometric procedures. The following digestive enzymes and BBEs were examined: $\alpha$-amylase (Foo \& Bais 1998), lipase (Winkler \& Stuckmann 1979), trypsin and chymotrypsin (Erlanger et al. 1961), acid phosphatase (ACP) (Abbott 1984), alkaline phosphatase (ALP) (Wenger et al. 1984) and leucine aminopeptidase (LAP) (Nagel et al. 1964). All enzymatic activity measurements were conducted at $25^{\circ} \mathrm{C}$ in triplicate and are presented as $\mathrm{U} \mathrm{g}^{-1}$ of protein, the quotient of enzyme units ( $\mu \mathrm{mol}$ of product $\mathrm{min}^{-1}$ ) in $1 \mathrm{~g}$ of total protein content, which was determined according to Lowry et al. (1951). The activities of ALP and LAP are presented as indexes, with ACP used as the divisor (ALP / ACP and LAP / ACP, calculated for each sample separately). All absorbance measurements were done with a M501 spectrophotometer (Camspec).

\subsection{Statistical analyses}

Statistical analysis of the numeric data was performed using Statistica 12 (StatSoft). Either 1- or 2way ANOVAs with Fisher's post hoc test were performed for all calculations, depending on whether the analysed data stemmed from one (final body mass, SGR, histomorphometry) or multiple (enzymatic analysis) time points. Differences were considered significant at $\mathrm{p}<0.05$ (SGR) or $\mathrm{p}<0.01$ (other measurements). Average values are displayed $\pm \mathrm{SD}$.

\section{RESULTS}

\subsection{Basic parameters and body content analysis}

Final survival rate, fish body mass, standard length and the results of whole-body content analysis are provided in Table 2. At the end of the experiment, the survival rate in group $Y$ was significantly lower than in groups $N$ and $X$. No statistically significant differences in body mass were recorded among the groups (even at $\mathrm{p}<0.05$ ), but the standard length of 
Table 2. Survival, measurements and body content analysis of juvenile crucian carp after 6 wk of experimental treatment $\left(N\right.$ : natural diet; $X$ and $Y_{i}$ commercial diet). Dry matter of the fish groups: $N=205 ; X=208.3 ; Y=195\left(\mathrm{~g} \mathrm{~kg}^{-1}\right.$ of wet weight). Superscript letters indicate significant differences among treatment groups (1-way ANOVA, p < 0.01). Means \pm SD are shown

\begin{tabular}{|lcrc|}
\hline & \multicolumn{4}{c|}{ Feeding treatment groups } \\
& $N$ & $X$ & $Y$ \\
\hline Survival (\%) & $97.8^{\mathrm{B}} \pm 1.4$ & $96.6^{\mathrm{B}} \pm 1.0$ & $90.9^{\mathrm{A}} \pm 2.0$ \\
Mean body mass (mg) & $583.5^{\mathrm{A}} \pm 280.5$ & $620.2^{\mathrm{A}} \pm 189$ & $582.9^{\mathrm{A}} \pm 156.1$ \\
Mean standard length (mm) & $26.86^{\mathrm{A}} \pm 3.63$ & $27.12^{\mathrm{A}} \pm 3.72$ & $25.39^{\mathrm{B}} \pm 2.01$ \\
& & & \\
Body content analysis (g kg & -1 & & \\
Total protein & of wet weight) & & \\
Crude fat & $147^{\mathrm{B}} \pm 4.5$ & $132.6^{\mathrm{A}} \pm 0.7$ & $129.4^{\mathrm{A}} \pm 1.8$ \\
Ash & $31.7^{\mathrm{A}} \pm 1.3$ & $55^{\mathrm{C}} \pm 1.5$ & $45.9^{\mathrm{B}} \pm 1$ \\
& $2.3^{\mathrm{C}} \pm 0.6$ & $1.65^{\mathrm{B}} \pm 0.4$ & $1.43^{\mathrm{A}} \pm 0.1$ \\
\hline
\end{tabular}

fish from group $Y$ was significantly lower than in the other 2 groups. In the whole-body content analysis, group $N$ was characterised by significantly higher protein and ash values and a lower fat content than groups $X$ and $Y$, while fish from group $X$ had the significantly highest body fat values. SGR differed significantly among groups only during the first 2 wk period, where group $N$ was characterised by a lower SGR $(p<0.05)$ than group $X$ (Fig. 2). Further information about other basic fish body parameters is presented and discussed extensively in Kasprzak et al. (2019).

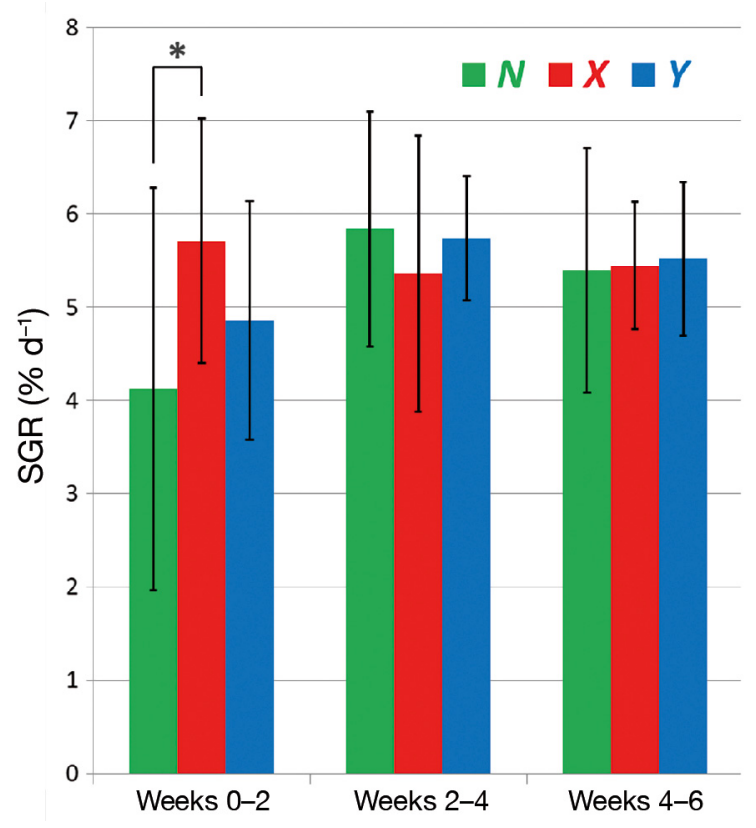

Fig. 2. Specific growth rates (SGR) of juvenile crucian carp during three 2 wk intervals of the experimental feeding treatment $(N$ : natural diet group; $X$ and $Y$; commercial diet groups; see Table 1); asterisk indicates significant difference among treatment groups (1-way ANOVA, $\mathrm{p}<0.05)$. Error bars are \pm SD

\subsection{Histological analysis of the digestive tract}

\subsubsection{Intestinal epithelium}

PCNA-positive enterocyte nuclei were found, only in the basal area of the mucosal folds, in all experimental groups (Fig. 3). Meanwhile, the anti-caspase staining did not provide satisfactory results and therefore apoptosis was not quantified in the intestine. Fish from group $N$ had the significantly highest mucosal folds and the highest proliferation percentage of enterocytes. Group $N$ also had different proportions of acidic and neutral mucous cells than groups $X$ and $Y$ (Table 3).

\subsubsection{Liver parenchyma}

Hepatocytes of fish from group $N$ were characterised by a significantly higher nuclear area and proliferation than in the other 2 groups, and the significantly lowest lipid content of the cytoplasm (Table 3, Fig. 4). Group $X$ had the lowest nuclear area, nucleo-cellular area index, proliferation and the highest lipid content, while hepatocytes in group $Y$ had the smallest total cell area. Apoptotic hepatocytes were scarce and their number did not differ significantly among the groups.

\subsubsection{Exocrine pancreas}

A distinct trend was observed in the cells of fish from group $N$, as they were significantly larger, had larger nuclei and a larger nuclear-cytoplasmic index, as well as a larger zymogen-filled area than the cells of fish from groups $X$ and $Y$. However, the zymogencytoplasmic index did not differ among any of the experimental groups (Table 3). In fish fed commercial diets, an overflow of adipose tissue (steatosis) among the tissues of the pancreas led to the dissipation of groups of exocrine secretory cells (Fig. 5).

\subsubsection{Skin fat}

During other observations of the longitudinal sections of fish, an excess of adipose tissue was noted in 


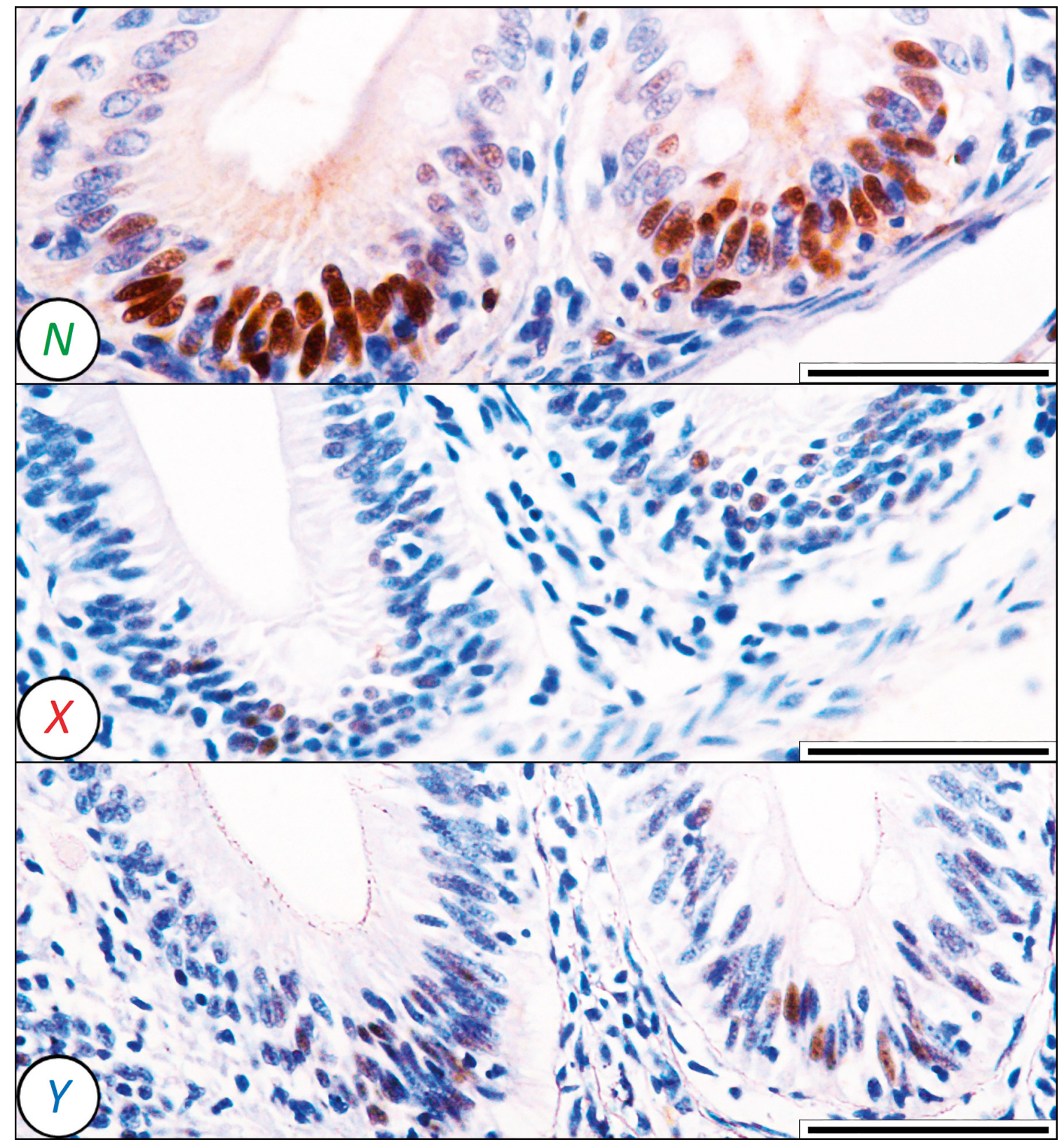

Fig. 3. Sections of intestinal folds of juvenile crucian carp after $6 \mathrm{wk}$ of experimental treatment with natural food $(N)$ or commercial diets $(X$ and $Y$ ) (see Table 1). Proliferating cell nuclear antigen (PCNA)-positive nuclei of enterocytes are stained brown. Immunohistochemical stain with anti-PCNA monoclonal antibody, counterstained with hematoxylin; scale = $100 \mu \mathrm{m}$

the skin of fish from groups $X$ and $Y$, on the bottom side of the abdominal cavity (Fig. 6).

\subsection{Digestive enzyme activity analyses}

The activities of amylase, lipase, trypsin and chymotrypsin are presented in Fig. 7. After 6 wk, the highest amylase activity was in group $Y$. The activity of lipase was significantly higher in $N$ than in the other 2 groups. On the contrary, both trypsin and chymotrypsin revealed identical activity patterns, with both $X$ and $Y$ groups characterised by approximately 3 times higher results than in group $N$.

The 2 graphs presenting ALP and LAP are similar (Fig. 8), because the activity indexes did not change after 2 and $4 \mathrm{wk}_{\text {; }}$ however, after $6 \mathrm{wk}$ one of the groups distinguished itself from the others with a significant activity growth. In the case of ALP it was the $X$ group, while in LAP it was group $Y$. 
Table 3. Histomorphometric measurements of the intestine, hepatocytes and exocrine pancreas cells of juvenile crucian carp after the 6 wk feeding experiment ( $N$ : natural diet; $X$ and $Y_{;}$commercial diet; see Table 1). Superscript letters indicate signifcant differences among treatment groups (1-way ANOVA [2-way ANOVA for quantity of mucous cells], $p<0.01$ ). FOV: field of view

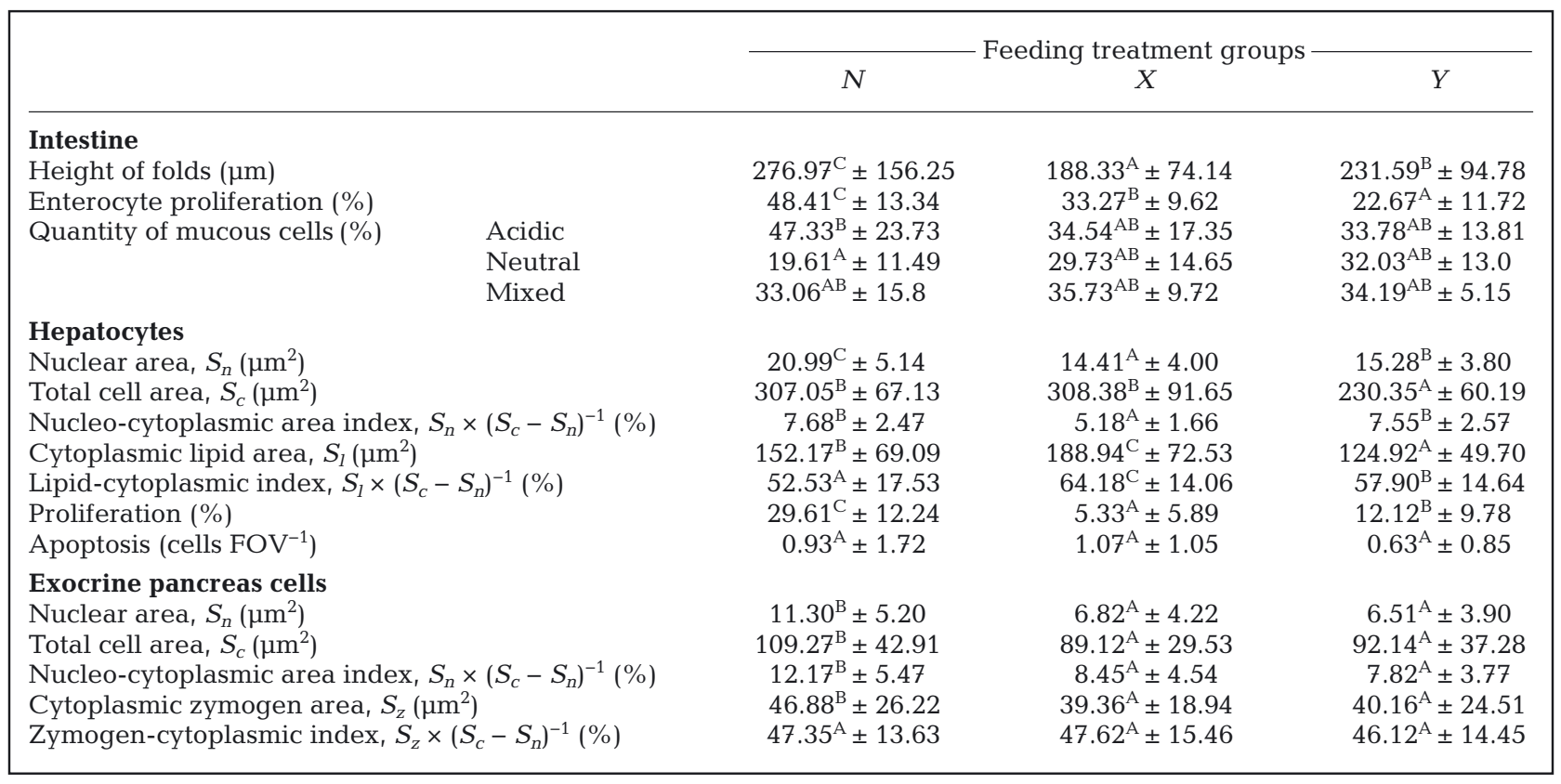

\section{DISCUSSION}

\subsection{General remarks}

The obvious diversity of the experimental feeding did not translate into any significant differences among the groups regarding the main production parameter - total body mass - and the SGR was almost identical after the first $2 \mathrm{wk}$ period. Therefore, this study evaluated the small details and nuances in morphology and physiology of the digestive tract, to determine whether the tested diets had a predominantly positive or negative effect on the development of crucian carp. The aim was to examine if such knowledge could be extrapolated for a feeding period longer than the duration of this experiment.

Fish fed diets $X$ and $Y$ had a lesser total-body content of ash and protein, but this was likely offset by their higher fat content; thus, no differences in total body mass were found. However, it has already been determined that the lower ash content in fish fed the 2 commercial diets was caused by skeletal demineralization, and the shorter standard length and lower survival of fish in group $Y$ was mostly related to skeletal deformities (Kasprzak et al. 2019). The results of whole-body content analysis are further discussed in Sections 4.2 and 4.3.

At the time of yolk sac absorption, the alimentary tract of many fish species, including the agastric cyprinids, is not fully developed (Dabrowski 1984). It was once thought that live food was essential for the development of fish larvae because this food source contains not only a balanced source of nutrients, but was also believed to be the origin of exogenous digestive enzymes which were needed to overcome early developmental deficiencies in the digestive tract (Lauff \& Hofer 1984). The importance of this foreign enzymatic activity in larval ontogeny was later discounted (Cahu \& Zambonino-Infante 2001). Nevertheless, live food does contribute to the course of digestion and absorption, likely due to specific nutrient fractions acting as activators, precursors or modulators of these processes (Kolkovski 2001, Zambonino-Infante \& Cahu 2007), and therefore it is still utilised in rearing programmes for many fish species (Kolkovski et al. 2009). Furthermore, the use of regular commercial diets shortly after hatching may cause diverse developmental alterations, as severe as skeletal deformities (Boglione et al. 2013), but also a variety of physiological and morphological defects in the digestive organs (Ostaszewska et al. 2005). Fish larvae tend to have very different nutritional requirements to those demanded by juveniles (Cahu \& Zambonino-Infante 2001), and it is very difficult to provide them with appropriately composed dry diets, which also need to be formulated separately for each species. In the case of Carassius carassius, 


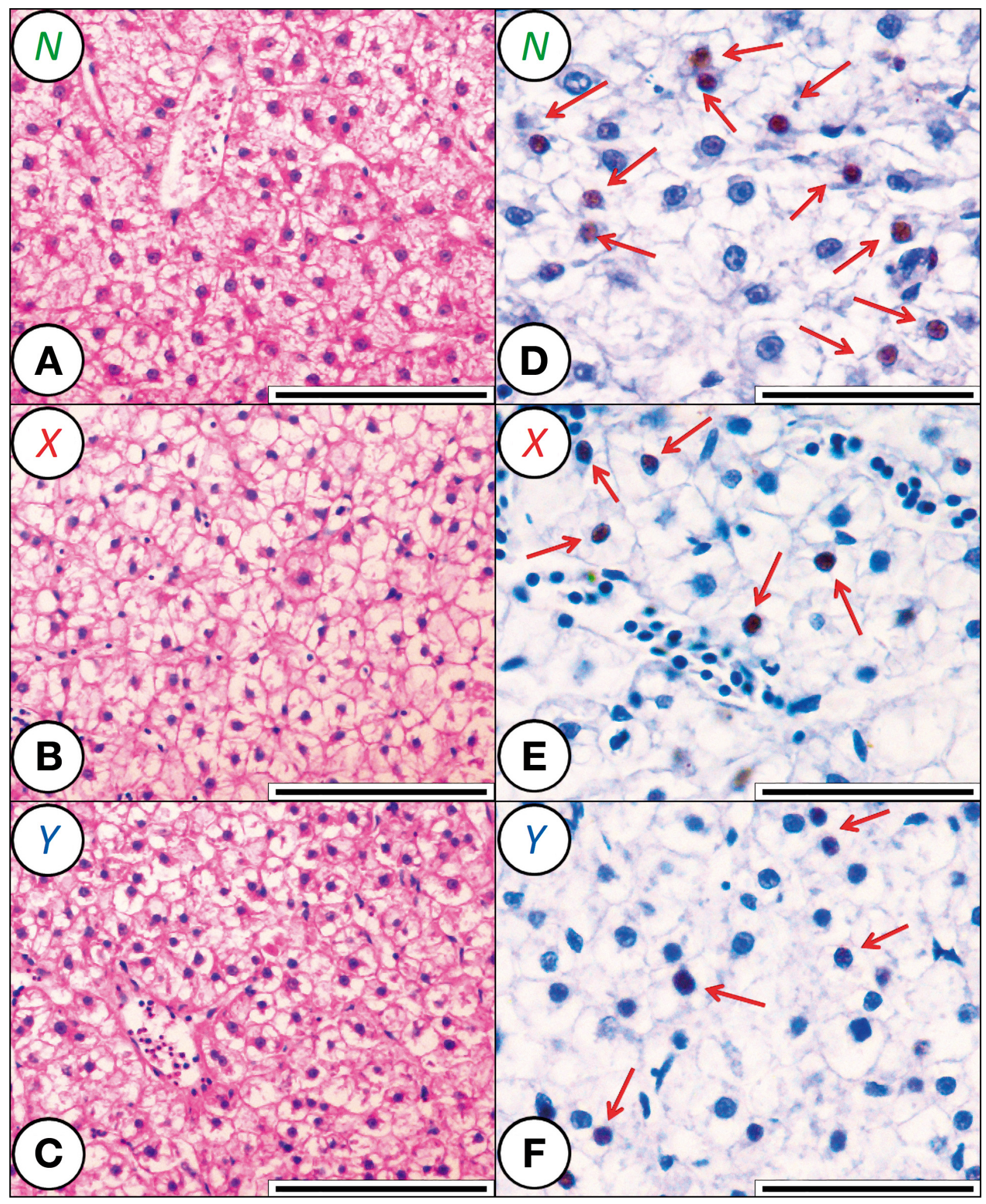

Fig. 4. Sections of juvenile crucian carp liver parenchyma, after 6 wk of experimental treatment with natural food ( $N$ ) or commercial diets $(X$ and $Y$ ) (see Table 1$)$. Arrows indicate brown-stained proliferating cell nuclear antigen (PCNA)-positive hepatocyte nuclei. $(\mathrm{A}, \mathrm{B}, \mathrm{C}) \mathrm{H} \& \mathrm{E}$ stain; scale $=100 \mu \mathrm{m}$. $(\mathrm{D}, \mathrm{E}, \mathrm{F})$ Immunohistochemical stain with anti-PCNA monoclonal antibody, counterstained with hematoxylin; scale $=50 \mu \mathrm{m}$ 


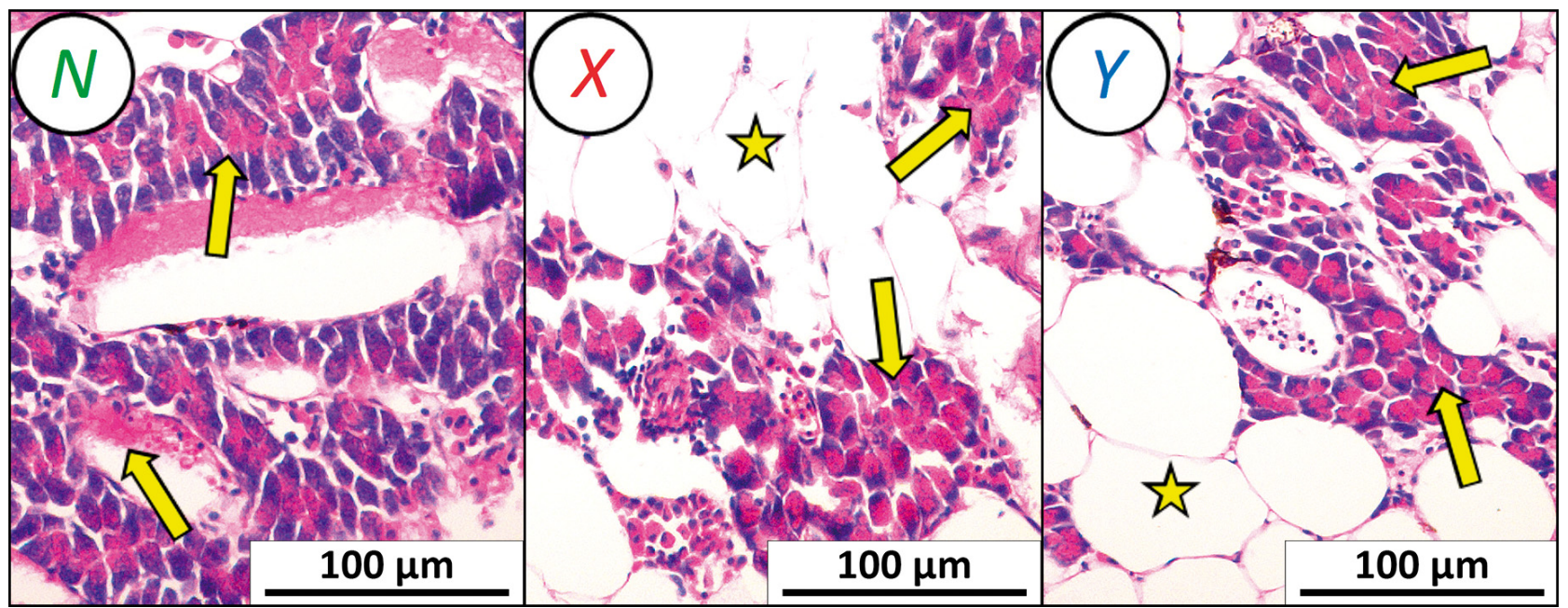

Fig. 5. Sections of the exocrine pancreas of juvenile crucian carp after 6 wk of experimental treatment with natural food $(N)$ or commercial diets ( $X$ and $Y$ ) (see Table 1). Arrows: zymogen; stars: adipose tissue. H\&E stain

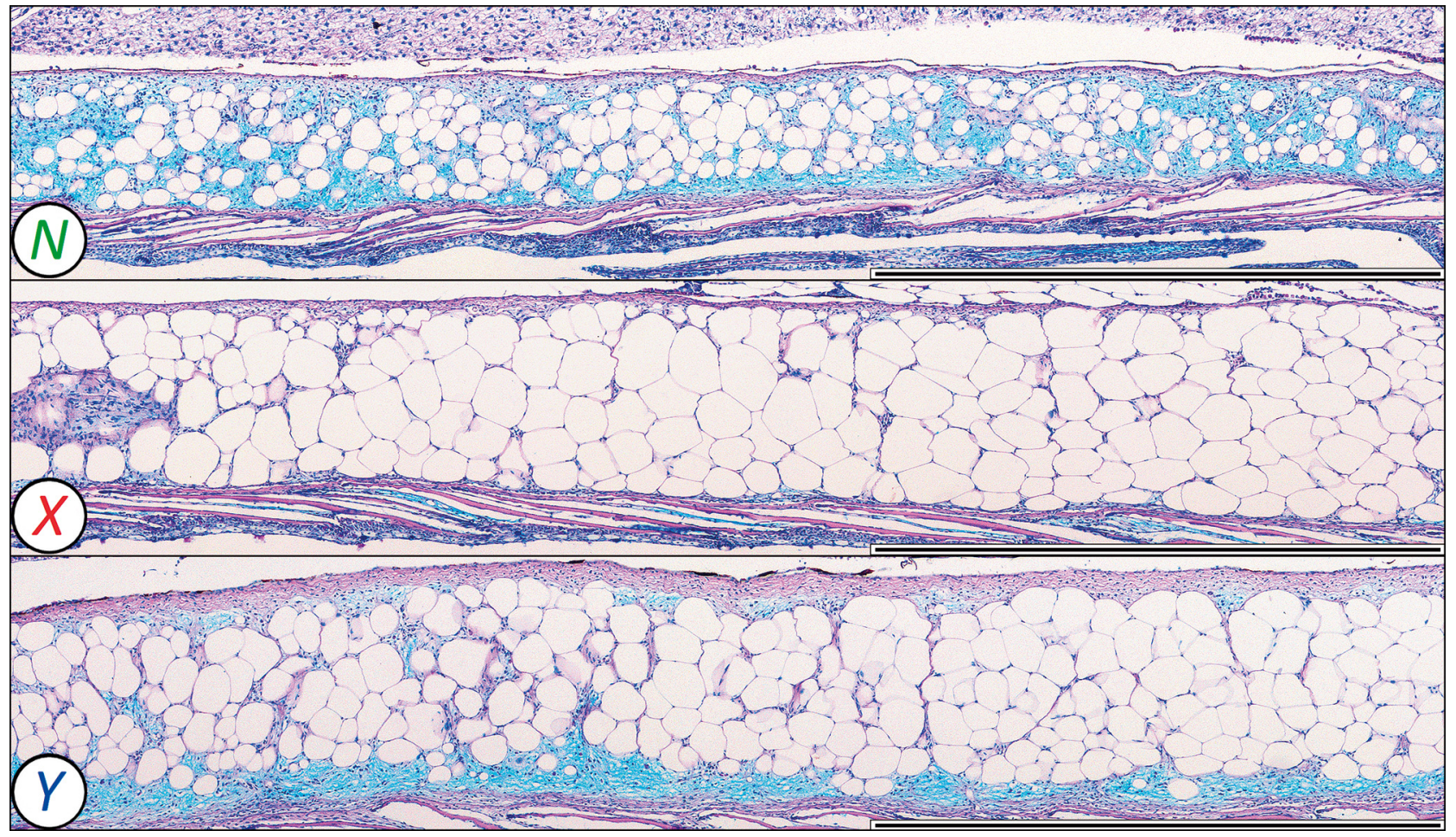

Fig. 6. Longitudinal sections of the skin fat on the bottom side of the abdominal cavity of juvenile crucian carp after 6 wk of experimental treatment with natural food $(N)$ or commercial diets $(X$ and $Y$ ) (see Table 1$)$. AB-PAS stain; scale = 1 mm

the application of a preliminary, Artemia-based rearing period throughout (at least) the first month of life is obligatory to prevent high mortality and morbid growth (Demény et al. 2012, Łączyńska et al. 2016), but the development of the digestive tract has not been studied before in their early juvenile stage.

\subsection{Histological analyses}

Immunohistochemical detection of PCNA is a reliable indicator of cellular proliferation in fish (Ortego et al. 1994) and it has already been applied in several studies on C. carassius (Margotta et al. 2001, Alfei et al. 2004, Sollid et al. 2005). Lower proliferation in- 

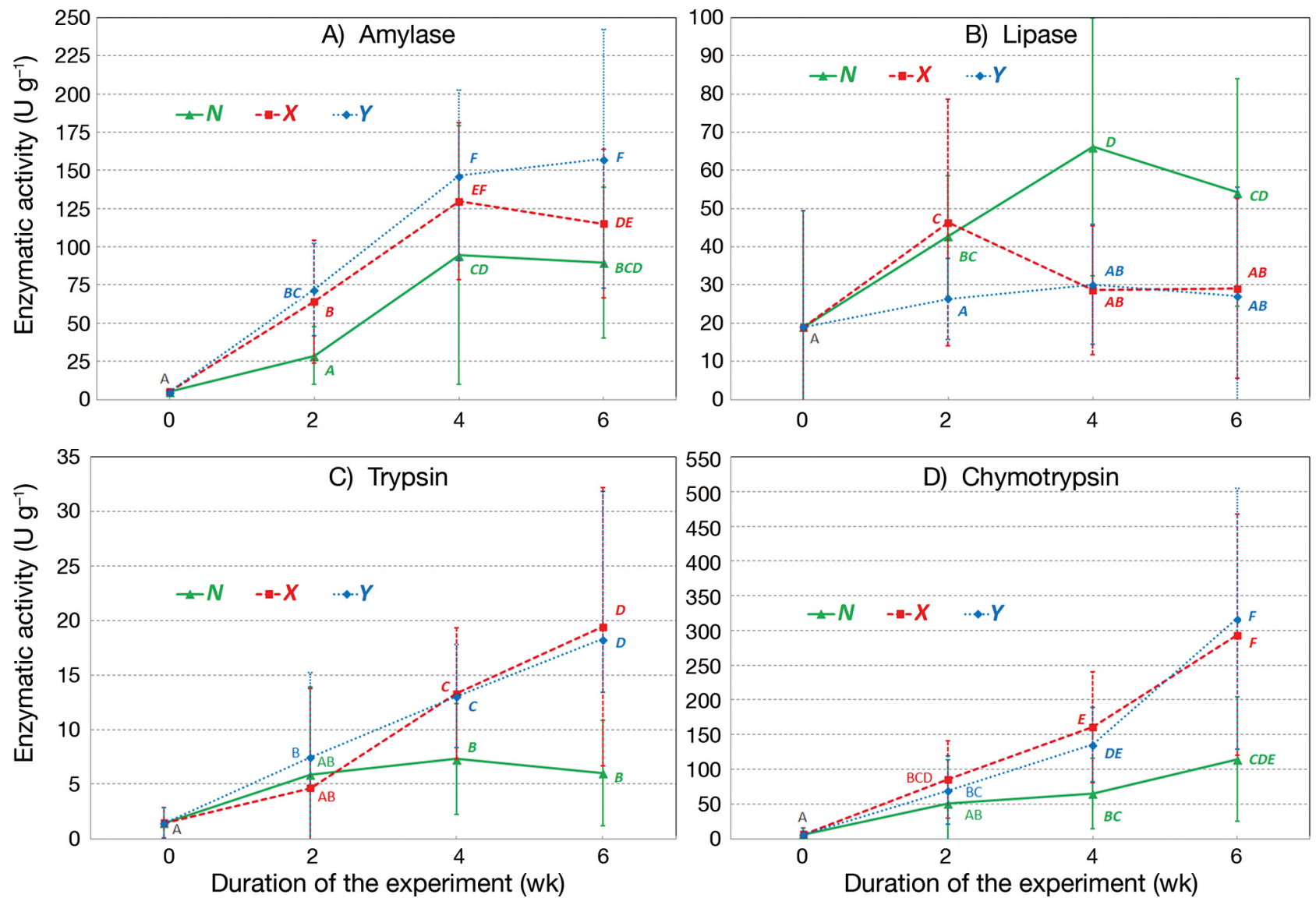

Fig. 7. Activities of (A) amylase, (B) lipase, (C) trypsin and (D) chymotrypsin throughout the feeding experiment with juvenile crucian carp ( $N$ : natural diet group; $X$ and $Y$; commercial diet group; see Table 1$)$; different letters reveal statistically significant differences among groups and/or sampling time points $(2$-way ANOVA, $\mathrm{p}<0.01)$; bold and italicized letters indicate significant differences among the particular sampling time points
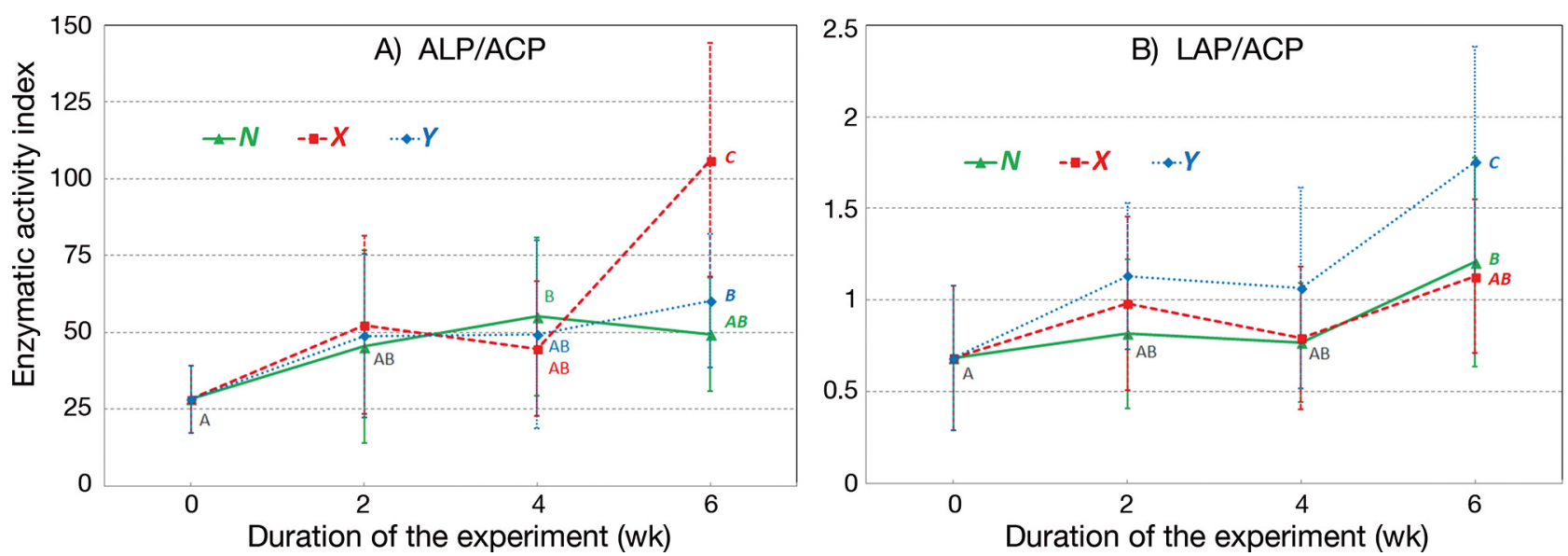

Fig. 8. Activity indexes of (A) alkaline phosphatase (ALP)/acid phosphatase (ACP) and (B) leucine aminopeptidase (LAP)/ACP throughout the feeding experiment with juvenile crucian carp $(N$ : natural diet group; $X$ and $Y$; commercial diet group; see Table 1); different letters reveal statistically significant differences among groups and/or sampling time points (2-way ANOVA, $\mathrm{p}<0.01$ ); bold and italicized letters indicate significant differences among the particular sampling time points 
dexes are recognised as signs of impaired tissue development or toxicity, whether in the liver (Kraugerud et al. 2012, Ostaszewska et al. 2016) or muscles (Ostaszewska et al. 2008), but elevated cell division may also be linked to inflammation and damage repair processes in the intestine (Sanden et al. 2005) or liver (Machado et al. 2014).

Higher enterocyte proliferation and longer intestinal folds (as recorded here in fish from group $N$ ) are recognized as indicators of better nutritional condition in reared fish (Baeverfjord \& Krogdahl 1996, Bakke-McKellep et al. 2007). Additional commentary about the mucosal folds is included in Section 4.3. Different proportions of acidic and neutral mucous cells recorded in fish fed commercial diets may indicate an abnormal secretion profile of the mucosa (Ostaszewska et al. 2010).

Overall hepatocyte area may reflect the amount of stored lipids and glycogen (Caballero et al. 1999) and such accumulation appears to be a reversible, nonpathological process (Castro et al. 2016). Meanwhile, the size of hepatocyte nuclei can be an indicator of their metabolic activity (Segner et al. 1988, Strüssmann \& Takashima 1990); therefore, diminished nuclei (as in groups $X$ and $Y$ ) may be markers of feeding inadequacies (Ostaszewska et al. 2005), although it should be noted that the nucleo-cellular index in group $Y$ did not differ from group $N$. General observations of the hepatocytes, however, revealed that the nuclei in group $N$ were usually round, while in groups $X$ and $Y$ other shapes occurred much more frequently. Furthermore, increased body fat levels, probably caused by impaired oxidative phosphorylation, are a common occurrence in phosphorusdeficient fish (Sugiura et al. 2004). Indeed, the cytoplasmic content of lipids in hepatocytes was higher in fish fed the 2 commercial diets than in fish from group $N$. Additionally, the lower hepatocyte proliferation in groups $X$ and $Y$ probably indicated that the development of the liver slowed down in these fish, especially when contrasted with the lack of differences in the numbers of apoptotic hepatocytes among the groups.

A similar principle regarding nuclear and cytoplasmic area could presumably also be applied to the exocrine pancreas cells, but only a handful of studies have shown the effects of malnutrition on the histological structure of this organ (Napora-Rutkowski et al. 2009). Furthermore, while extensive pancreatic steatosis (observed in $X$ and $Y$ ) may lead to an impairment of proenzymatic production (Kamaszewski et al. 2010), the measurements did not show any differences regarding the proportion of cytoplasmic zymogen content, and the causes for this pathology are not known even in medical research (Smits \& van Geenen 2011). Overall, it cannot be denied that the morphology of exocrine pancreas cells was visibly different between group $N$ and groups $X$ and $Y$.

Histomorphometrics revealed a distinct trend, as all of the parameters reached their highest values in group $N$, which may suggest a better overall condition of the digestive tracts of the fish in this group.

\subsection{Enzymatic analyses}

Amylase activity correlates with dietary carbohydrate content (Li et al. 2016), but high values of dietary lipids may impair the utilisation of these carbohydrates (Rueda-Jasso et al. 2004). In this study, amylase activity stabilised in all 3 groups after $4 \mathrm{wk}$, implying that the differences between groups were likely a result of an unspecified regulatory mechanism. Amylolytic activity in fish is still largely overlooked, but a number of studies have already shown the positive effects of carbohydrase supplementation (e.g. Castillo \& Gatlin 2015).

Dietary lipids are extremely important in the early stages of fish growth (Izquierdo et al. 2000). Activity graphs of lipase were opposite to the dietary crude fat content, unsurprisingly, because it is the level and proportions of certain triglycerides that are recognised as modulators of lipolytic activity (Cahu \& Zambonino-Infante 2001). Low lipase activity in fish fed dry food suggests that both diets comprise a fatty acid content which is unfavourable for juvenile crucian carp. Freshwater fish require more dietary $n-6$ than $n$-3 highly unsaturated fatty acids (HUFAs) (Kamler et al. 2008). Lastly, the much higher lipase activity in group $N$ might relate directly to the higher hepatocyte volume in these fish due to an increased amount of processed lipids.

Lower trypsin and chymotrypsin activities in the fish fed natural food corresponded with the lesser total protein content of that diet, which is in accordance with various reports (Zambonino-Infante \& Cahu 2007). However, the constant active increase of these enzymes throughout the experiment in fish fed both dry diets might have been an emergency response to borderline malnutrition, in order to maximise the utilisation of injested peptides (Cara et al. 2007). This is likely a result of an imbalanced amino acid supply, which is a common problem in fish fed artificial protein sources (Rønnestad et al. 2013).

Overall, the combined activity graphs of 4 pancreatic enzymes showed that the digestion pattern for natural food differed significantly from the 2 nearly 
identical patterns of the commercial feeds. This shows a noteworthy flexibility of juvenile C. carassius to adjust to diverse dietary compositions by varying the blend of pancreatic secretions.

Enterocyte maturation is essential for the ongoing development of fish larvae because it leads to an increase of epithelial digestion and absorption (Cahu \& Zambonino-Infante 1995). Over time, pancreatic peptidases lose significance in favour of intestinal BBEs, but simple activity measurements are insufficient for a thorough examination of this process. The calculation of an activity ratio of a selected BBE and an intracellular digestive enzyme provides a better representation of the progressive brush border development (Cahu \& Zambonino-Infante 2001). A similar approach was used in this paper, but ACP was used in place of the Leu-Ala peptidase as the referential enzyme. Studies on fish enterocytes have revealed that ACP is usually associated with lysosomes and vesicular transport (Bakke-McKellep et al. 2000, Faccioli et al. 2016), which supports previous findings considering ACP participation in pinocytotic absorption and digestion (Govoni et al. 1986). Intestinal ACP activity stabilises after early fluctuations during larval metamorphosis (Zacarias-Soto et al. 2013); therefore, we suggest that ACP may be used as an intracellular reference for $\mathrm{BBE}$ analysis in fish which have already passed the larval transformation.

Intestinal ALP is a multifunctional enzyme because it modulates the surface $\mathrm{pH}$ of the mucosa, shapes the microbial community in the tract, regulates lipid absorption and participates in the anti-inflammatory response in the intestine (Lallès 2014). Increasing ALP activity during early larval growth marks the transition to an adult type of digestion due to the development of the brush border (Kolkovski et al. 2009). However, the distinct activity spike observed in group $X$ after 6 wk does not necessarily imply that enterocyte maturation processes suddenly accelerated in that particular group. A study on the development of microbial communities in goldfish concluded that these bacterial populations establish around 2 mo post-hatching (Sugita et al. 1988), which occurred exactly between the 4 and $6 \mathrm{wk}$ sampling points in our study. Feeding-induced changes in intestinal microbiota composition are not uncommon in fish breeding (Wang et al. 2017); therefore, it is possible that a microbiological distortion occurred in the $X$ group which led to an anti-inflammatory response of the epithelium. In support of this theory, adverse microbial changes in the intestine may coincide with shortened intestinal villi, as was observed in group $X$ (Heikkinen et al. 2006), while the dietary addition of probiotic bacteria may promote elongation of intestinal folds (Anguiano et al. 2013).

LAP is a highly specific BBE (Ma et al. 2005). Enterocyte maturation in fish larvae is commonly assessed with activity measurements of both ALP and LAP (Vizcaíno et al. 2014, Gu et al. 2016). However, the observed pattern was not similar to ALPs because the highest activity was recorded in group $Y$. This may be another example of a dietary-specific response due to the intake of an as yet undetermined nutritional component (Cahu \& Zambonino-Infante 2001). Moreover, increased intestinal LAP may mirror liver damage (Feng et al. 2017). We assume that the higher LAP activity in group $Y$ occurred in response to malnutrition as an attempt to increase mucosal digestion.

\section{CONCLUSIONS}

This study has shown that neither of the applied commercial diets appear to satisfy the nutritional demands of juvenile crucian carp, even though initial conclusions based on fish growth rates and survival might have been different. In a previous article (Kasprzak et al. 2019) it was revealed that crucian carp fed the 2 examined diets were characterised by a multitude of skeletal disorders; the current study showed that the alimentary tracts of these fish were also visibly affected by the employed dry feeds. Among the described observations, the activity patterns of digestive enzymes and an excessive accumulation of lipids are probably the most pronounced evidence of the inadequacy of these diets. While the general production parameters initially appeared to be very promising, it now seems reasonable to conclude that the chances of survival (and propagation) of these fish would be lower than those of fish fed natural food (upon release into their natural environment), especially after a rearing period which would last longer than the $6 \mathrm{wk}$ shown in the present experiment. The described dietary effects would very likely continue to accumulate, to a point where they would significantly affect the overall condition of these fish, especially by weakening their ability to avoid predators or compete for food due to diminished mobility caused by deformities and malnutrition.

These results highlight that much more work still needs to be done regarding rearing protocols for juvenile crucian carp. It is obvious now that developing formulated diets specifically for individual species is necessary when accounting for the performance and welfare of the cultured fish, rather than being just an economical improvement of the pro- 
duction process. This is also a tangible example of how deceiving initial growth data might be in fisheries, highlighting that additional scientific verification is valuable and that advanced analyses should always be performed in such studies.

Acknowledgements. This paper is based on R.K.'s PhD dissertation. The experiment was conducted according to the permit no. 18/2015, issued by the 3rd Local Ethical Committee for Experiments on Animals in Warsaw (23.04.2015). The research was supplied with an internal faculty grant no. N00378-99, funded by the Faculty of Animal Science at the Warsaw University of Life Sciences.

\section{LITERATURE CITED}

Abbott L (1984) Acid phosphatase. In: Kaplan LA, Pesce AJ (eds) Clinical chemistry. The CV Mosby Company, St. Louis, MO, p 1079-1083

Alfei L, Margotta V, Morelli A, Gelosi E (2004) PCNA-positive cerebellar cells in an adult teleost, Carassius carassius L. Rend Lincei-Sci Fis 15:43-55

Anguiano M, Pohlenz C, Buentello A, Gatlin DM III (2013) The effects of prebiotics on the digestive enzymes and gut histomorphology of red drum (Sciaenops ocellatus) and hybrid striped bass (Morone chrysops $\times$ M. saxatilis). Br J Nutr 109:623-629

Baeverfjord G, Krogdahl Å (1996) Development and regression of soybean meal induced enteritis in Atlantic salmon, Salmo salar L., distal intestine: a comparison with the intestines of fasted fish. J Fish Dis 19:375-387

* Bakke-McKellep AM, Press CM, Baeverfjord G, Krogdahl $\AA$, Landsverk T (2000) Changes in immune and enzyme histochemical phenotypes of cells in the intestinal mucosa of Atlantic salmon, Salmo salar L., with soybean meal induced enteritis. J Fish Dis 23:115-127

Bakke-McKellep AM, Penn MH, Salas PM, Refstie S and others (2007) Effects of dietary soyabean meal, inulin and oxytetracycline on intestinal microbiota and epithelial cell stress, apoptosis and proliferation in the teleost Atlantic salmon (Salmo salar L.). Br J Nutr 97:699-713

Boglione C, Gisbert E, Gavaia P, Witten PE and others (2013) Skeletal anomalies in reared European fish larvae and juveniles. Part 2: Main typologies, occurrences and causative factors. Rev Aquacult 5:S121-S167

Caballero MJ, López-Calero G, Socorro J, Roo FJ, Izquierdo MS, Férnandez AJ (1999) Combined effect of lipid level and fish meal quality on liver histology of gilthead seabream (Sparus aurata). Aquaculture 179:277-290

Cahu CL, Zambonino-Infante JL (1995) Effect of the molecular form of dietary nitrogen supply in sea bass larvae: response of pancreatic enzymes and intestinal peptidases. Fish Physiol Biochem 14:209-214

Cahu CL, Zambonino-Infante JL (2001) Substitution of live food by formulated diets in marine fish larvae. Aquaculture 200:161-180

* Cara B, Moyano FJ, Zambonino-Infante JL, Fauvel C (2007) Trypsin and chymotrypsin as indicators of nutritional status of post-weaned sea bass larvae. J Fish Biol 70: 1798-1808

* Castillo S, Gatlin DM III (2015) Dietary supplementation of exogenous carbohydrase enzymes in fish nutrition: a review. Aquaculture 435:286-292

* Castro C, Couto A, Pérez-Jiménez A, Serra CR and others (2016) Effects of fish oil replacement by vegetable oil blend on digestive enzymes and tissue histomorphology of European sea bass (Dicentrarchus labrax) juveniles. Fish Physiol Biochem 42:203-217

* Dabrowski K (1984) The feeding of fish larvae: present «state of the art» and perspectives. Reprod Nutr Dev 24: 807-833

*De Giosa M, Czerniejewski P, Rybczyk A (2014) Seasonal changes in condition factor and weight-length relationship of invasive Carassius gibelio (Bloch, 1782) from Leszczynskie Lakeland, Poland. Adv Zool 2014:678763

* Demény F, Trenovszki MM, Sokoray-Varga S, Hegyi Á and others (2012) Relative efficiencies of Artemia nauplii, dry food and mixed food diets in intensive rearing of larval crucian carp (Carassius carassius L.). Turk J Fish Aquat Sci 12:691-698

Erlanger BF, Kokowsky N, Cohen W (1961) The preparation and properties of two new chromogenic substrates of trypsin. Arch Biochem Biophys 95:271-278

* Faccioli CK, Chedid RA, Mori RH, do Amaral AC, Franceschini-Vicentini IB, Vicentini CA (2016) Acid and alkaline phosphatase localization in the digestive tract mucosa of the Hemisorubim platyrhynchos. Acta Histochem 118: 722-728

Feng GD, He J, Ao X, Chen DW (2017) Effects of maize naturally contaminated with aflatoxin $\mathrm{B}_{1}$ on growth performance, intestinal morphology, and digestive physiology in ducks. Poult Sci 96:1948-1955

Foo AY, Bais R (1998) Amylase measurement with 2-chloro4-nitrophenyl maltotrioside as substrate. Clin Chim Acta 272:137-147

Govoni JJ, Boehlert GW, Watanabe Y (1986) The physiology of digestion in fish larvae. Environ Biol Fishes 16:59-77

*Gu M, Bai N, Zhang Y, Krogdahl A (2016) Soybean meal induces enteritis in turbot Scophthalmus maximus at high supplementation levels. Aquaculture 464:286-295

*Hänfling B, Bolton P, Harley M, Carvalho GR (2005) A molecular approach to detect hybridisation between crucian carp (Carassius carassius) and non indigenous carp species (Carassius spp. and Cyprinus carpio). Freshw Biol 50:403-417

* Heikkinen J, Vielma J, Kemiläinen O, Tiirola M and others (2006) Effects of soybean meal based diet on growth performance, gut histopathology and intestinal microbiota of juvenile rainbow trout (Oncorhynchus mykiss). Aquaculture 261:259-268

* Izquierdo MS, Socorro J, Arantzamendi L, Hernández-Cruz CM (2000) Recent advances in lipid nutrition in fish larvae. Fish Physiol Biochem 22:97-107

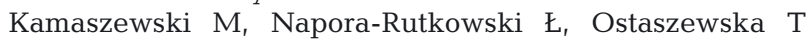
(2010) Effect of feeding on digestive enzyme activity and morphological changes in the liver and pancreas of pikeperch (Sander lucioperca). Bamidgeh 62:225-236

Kamler E, Wolnicki J, Kamiński R, Sikorska J (2008) Fatty acid composition, growth and morphological deformities in juvenile cyprinid, Scardinius erythrophthalmus fed formulated diet supplemented with natural food. Aquaculture 278:69-76

Kasprzak R, Ostaszewska T, Wagner B (2019) The effect of feeding commercial diets on the development of juvenile crucian carp (Carassius carassius, L.). Part 1: Skeletal deformations. Aquac Nutr 25:78-87

Kolkovski S (2001) Digestive enzymes in fish larvae and 
juveniles - implications and applications to formulated diets. Aquaculture 200:181-201

Kolkovski S, Lazo J, Leclercq D, Izquierdo M (2009) Fish larvae nutrition and diet: new developments. In: Burnell $G$, Allan G (eds) New technologies in aquaculture: improving production efficiency, quality and environmental management. Woodhead Publishing, Cambridge, p 315-369

Kraugerud M, Doughty RW, Lyche JL, Berg V and others (2012) Natural mixtures of persistent organic pollutants (POPs) suppress ovarian follicle development, liver vitellogenin immunostaining and hepatocyte proliferation in female zebrafish (Danio rerio). Aquat Toxicol 116-117: $16-23$

Łączyńska B, Palińska-Żarska K, Nowosad J, Biłas M and others (2016) Effect of age, size and digestive tract development on weaning effectiveness in crucian carp, Carassius carassius (Linnaeus, 1758). J Appl Ichthyology 32:866-872

Lallès JP (2014) Intestinal alkaline phosphatase: novel functions and protective effects. Nutr Rev 72:82-94

Lauff M, Hofer R (1984) Proteolytic enzymes in fish development and the importance of dietary enzymes. Aquaculture 37:335-346

Li X, Zhu X, Han D, Yang Y, Jin J, Xie S (2016) Carbohydrate utilization by herbivorous and omnivorous freshwater fish species: a comparative study on gibel carp (Carassius auratus gibelio. var CAS III) and grass carp (Ctenopharyngodon idellus). Aquac Res 47:128-139

Lowry OH, Rosebrough NJ, Farr AL, Randall RJ (1951) Protein measurement with the Folin phenol reagent. J Biol Chem 193:265-275

Ma H, Cahu CL, Zambonino-Infante JL, Yu H, Duan Q, Le Gall MM, Mai K (2005) Activities of selected digestive enzymes during larval development of large yellow croaker (Pseudosciaena crocea). Aquaculture 245:239-248

* Machado SP, Cunha V, Reis-Henriques MA, Ferreira M (2014) Histopathological lesions, P-glycoprotein and PCNA expression in zebrafish (Danio rerio) liver after a single exposure to diethylnitrosamine. Environ Toxicol Pharmacol 38:720-732

Margotta V, Morelli A, Gelosi E, Alfei L (2001) PCNA positivity in the telencephalic matrix areas in the adult of a teleost, Carassius carassius L. Rend Lincei-Sci Fis 12: 105-115

Myszkowski L, Kamiński R, Quiros M, Stanny LA, Wolnicki J (2002) Dry diet-influenced growth, size variability, condition and body deformities in juvenile crucian carp Carassius carassius L. reared under controlled conditions. Arch Pol Fisheries 20:157-163

Nagel W, Willig F, Schmidt FH (1964) On amino acid arylamidase (so-called leucine aminopeptidase) activity in the human serum. Klin Wochenschr 42:447-449

Napora-Rutkowski L, Kamaszewski M, Bielawski W, Ostaszewska T, Wegner A (2009) Effects of starter diets on pancreatic enzyme activity in juvenile sterlet (Acipenser ruthenus). Bamidgeh 61:143-150

* Ortego LS, Hawkins WE, Walker WW, Krol RM, Benson WH (1994) Detection of proliferating cell nuclear antigen in tissues of three small fish species. Biotech Histochem 69: $317-323$

₹ Ostaszewska T, Dabrowski K, Palacios ME, Olejniczak M, Wieczorek M (2005) Growth and morphological changes in the digestive tract of rainbow trout (Oncorhynchus mykiss) and pacu (Piaractus mesopotamicus) due to casein replacement with soybean proteins. Aquaculture 245:273-286
Ostaszewska T, Dabrowski K, Wegner A, Krawiec M (2008) The effects of feeding on muscle growth dynamics and the proliferation of myogenic progenitor cells during pike perch development (Sander lucioperca). J World Aquac Soc 39:184-195

Ostaszewska T, Dabrowski K, Kamaszewski M, Grochowski P, Verri T, Rzepkowska M, Wolnicki J (2010) The effect of plant protein-based diet supplemented with dipeptide or free amino acids on digestive tract morphology and PepT1 and PepT2 expressions in common carp (Cyprinus carpio L.). Comp Biochem Physiol A Mol Integr Physiol 157:158-169

Ostaszewska T, Chojnacki M, Kamaszewski M, SawoszChwalibóg E (2016) Histopathological effects of silver and copper nanoparticles on the epidermis, gills, and liver of Siberian sturgeon. Environ Sci Pollut Res 23: 1621-1633

* Ribeiro F, Rylková K, Moreno-Valcárcel R, Carrapato C, Kalous L (2015) Prussian carp Carassius gibelio: a silent invader arriving to the Iberian Peninsula. Aquat Ecol 49: 99-104

Ricker WE (1979) Growth rates and models. In: Hoar WS, Randall DJ, Brett JR (eds) Fish physiology, Vol 8. Bioenergetics and growth. Academic Press, New York, NY, p $677-743$

* Rønnestad I, Yúfera M, Ueberschär B, Ribeiro L, Sæle Ø, Boglione C (2013) Feeding behaviour and digestive physiology in larval fish: current knowledge, and gaps and bottlenecks in research. Rev Aquacult 5:S59-S98

Rueda-Jasso R, Conceiçao LE, Dias J, De Coen W and others (2004) Effect of dietary non-protein energy levels on condition and oxidative status of Senegalese sole (Solea senegalensis) juveniles. Aquaculture 231:417-433

* Sanden M, Berntssen MHG, Krogdahl Å, Hemre GI, BakkeMcKellep AM (2005) An examination of the intestinal tract of Atlantic salmon, Salmo salar L., parr fed different varieties of soy and maize. J Fish Dis 28:317-330

* Sayer CD, Copp GH, Emson D, Godard MJ, Zi ba G, Wesley KJ (2011) Towards the conservation of crucian carp Carassius carassius: understanding the extent and causes of decline within part of its native English range. J Fish Biol 79:1608-1624

Segner H, Rösch R, Schmidt H, von Poeppinghausen KJ (1988) Studies on the suitability of commercial dry diets for rearing of larval Coregonus lavaretus from Lake Constance. Aquat Living Resour 1:231-238

พ Sikorska J, Kondera E, Kamiński R, Ługowska K, Witeska M, Wolnicki J (2018) Effect of four rearing water temperatures on some performance parameters of larval and juvenile crucian carp, Carassius carassius, under controlled conditions. Aquac Res 49:3874-3880

Smits MM, van Geenen EJM (2011) The clinical significance of pancreatic steatosis. Nat Rev Gastroenterol Hepatol 8: 169-177

* Sollid J, Kjernsli A, De Angelis PM, Røhr ÅK, Nilsson GE (2005) Cell proliferation and gill morphology in anoxic crucian carp. Am J Physiol Regul Integr Comp Physiol 289:R1196-R1201

K Strüssmann CA, Takashima F (1990) Hepatocyte nuclear size and nutritional condition of larval pejerrey, Odontesthes bonariensis (Cuvier et Valenciennes). J Fish Biol 36:59-65

Sugita H, Tsunohara M, Ohkoshi T, Deguchi Y (1988) The establishment of an intestinal microflora in developing goldfish (Carassius auratus) of culture ponds. Microb Ecol 15:333-344 
Sugiura SH, Hardy RW, Roberts RJ (2004) The pathology of phosphorus deficiency in fish - a review. J Fish Dis 27: 255-265

Tarkan AS, Copp GH, Zi ba G, Godard MJ, Cucherousset J (2009) Growth and reproduction of threatened native crucian carp Carassius carassius in small ponds of Epping Forest, south-east England. Aquat Conserv 19:797-805

Tarkan AS, Gaygusuz Ö, Gürsoy Gaygusuz Ç, Saç G, Copp GH (2012) Circumstantial evidence of gibel carp, Carassius gibelio, reproductive competition exerted on native fish species in a mesotrophic reservoir. Fish Manag Ecol 19:167-177

Tarkan AS, Almeida D, Godard MJ, Gaygusuz Ö and others (2016) A review and meta analysis of growth and life history traits of a declining European freshwater fish, crucian carp Carassius carassius. Aquat Conserv 26: 212-224

Vizcaíno AJ, López G, Sáez MI, Jiménez JA and others (2014) Effects of the microalga Scenedesmus almeriensis as fishmeal alternative in diets for gilthead sea bream, Sparus aurata, juveniles. Aquaculture 431:34-43

Wang AR, Ran C, Ringø E, Zhou ZG (2017) Progress in fish gastrointestinal microbiota research. Rev Aquacult 10: 626-640

Wenger C, Kaplan A, Rubaltelli FF, Hammerman C (1984)

Editorial responsibility: Helmut Segner,

Bern, Switzerland
Alkaline phosphatase. In: Kaplan LA, Pesce AJ (eds) Clinical chemistry. The CV Mosby Company, St. Louis, MO, p 1094-1098

Winkler UK, Stuckmann M (1979) Glycogen, hyaluronate, and some other polysaccharides greatly enhance the formation of exolipase by Serratia marcescens. J Bacteriol 138:663-670

* Wouters J, Janson S, Lusková V, Olsén KH (2012) Molecular identification of hybrids of the invasive gibel carp Carassius auratus gibelio and crucian carp Carassius carassius in Swedish waters. J Fish Biol 80:2595-2604

*Zacarias-Soto M, Barón-Sevilla B, Lazo JP (2013) Ontogeny and distribution of alkaline and acid phosphatases in the digestive system of California halibut larvae (Paralichthys californicus). Fish Physiol Biochem 39: 1331-1339

* Zambonino-Infante JL, Cahu CL (2007) Dietary modulation of some digestive enzymes and metabolic processes in developing marine fish: applications to diet formulation. Aquaculture 268:98-105

之这arski D, Targońska K, Krejszeff S, Kwiatkowski M, Kupren K, Kucharczyk D (2011) Influence of stocking density and type of feed on the rearing of crucian carp, Carassius carassius (L.), larvae under controlled conditions. Aquac Int 19:1105-1117

Submitted: April 1, 2019; Accepted: August 20, 2019 Proofs received from author(s): November 18, 2019 